\title{
EU/OUTRO (DES)MASCARADO: TRANSGRESSÕES AUTORAIS EM PUBLICAÇÃO DE FANFICTION
}

\begin{abstract}
Juliene da Silva Marques ${ }^{1}$
Resumo: Com base na Análise de Discurso de linha francesa, esta pesquisa investiga a autoria na produção de fanfiction, tendo como base a narrativa "Cellbit, a vida com MITW", de Titia_Little, que coloca em cena, como protagonistas, influenciadores digitais. O objetivo é investigar a transgressão autoral que subjetiva as minorias perante o eu/outro, dando destaque à relação estabelecida entre autora, leitoras e influenciador digital. Para tanto, recortes de interação serão investigados a fim de verificar as transgressões ocorridas a partir da produção desse gênero textual que se baseia em sentidos outros para visibilizar, também, sujeitos e contextos outros, não-normativos e marginalizados em narrativas oficiais. Palavras-chave: Fanfiction; Autoria; Análise de Discurso.

Absubstract: Based on the French Discourse Analysis theory, this research investigates authorship in the production of fanfiction, based on the narrative "Cellbit, a vida com MITW", by Titia_Little, which puts on stage, as protagonists, digital influencers. The objective is to investigate the authorial transgression that subjective minorities to the self / other, emphasizing the relationship established between the author, readers and digital influencer. To this end, clippings of interaction will be investigated in order to verify the transgressions that occurred from the production of this textual genre, which is based on other meanings to also make subjects and other contexts, non-normative and marginalized in official narratives, visible.
\end{abstract}

Keywords: Fanfiction; Authorship; Discourse Analysis.

1 Professora do Instituto Federal de Educação, Ciência e Tecnologia do Rio Grande do Sul, Campus Restinga. E-mail: juliene.marques@hotmail.com 


\section{INTRODUÇÃO}

Diferentemente do que se ouve de modo repetitivo em ambiente escolar, como "ninguém gosta de escrever", "as pessoas não costumam ler", "só escrevo/leio por obrigação" entre outros, existe um universo no qual há escrita, há leitura e, acima de tudo, há colaboração. Esse universo se chama fanfiction ${ }^{2}$. Essa materialidade narrativa se configura tradicionalmente a partir de um universo diegético já existente, destinando-se, principalmente, a narrativas literárias. No entanto, atualmente, há um direcionamento novo para as publicações de fanfictions: os influenciadores digitais.

A fanfiction se configura como um universo próprio de narrativa, diferenciando-se e ficando, muitas vezes, à margem das publicações legitimadas socialmente. Essa questão se dá devido a alguns fatores: desconexão do mercado editorial devido a não objetivar lucros ${ }^{3}$ ou adequação ao que se tem como paradoxo para publicação; ocorrência em lugar não-institucional; produção, em maioria, a partir do gênero feminino (mulheres cis e $\operatorname{trans}{ }^{4}$ ) com baixo poder aquisitivo; abordagem de temáticas não usuais na cultura clássica de edições, com destaque para os romances homossexuais que contemplam atos sexuais homoafetivos ${ }^{5}$ (JAMISON, 2017).

A partir desse contexto, esta pesquisa delimitou-se, pois a materialidade para análise, a fanfiction "Cellbit, a vida com MITW", de Titia_Little 6 , baseia-se em influenciadores digitais e dialoga com suas leitoras para se construir de modo colaborativo, o que é característico nos ambientes virtuais em que elas são publicadas.

Destaca-se, assim, como problema de pesquisa a necessidade de investigar a seguinte questão: como se dá a autoria de minorias (des)mascaradas diante da produção narrativa sobre os influenciadores digitais? Para tecer a discussão a respeito, ter-se-ão, como base teórica, as perspectivas da Análise de Discurso (AD) de linha francesa, por esta interrogar a construção de sentidos levando em conta as condições de produção de cada sujeito (ORLANDI, 2017, p. 282).

Com isso, delimitou-se como objetivo desta pesquisa a ação de investigar a transgressão no movimento de autoria que constitui a subjetivação das minorias diante do eu/outro digit(re)al, tendo como base a materialidade discursiva da fanfiction sobre influenciadores digitais. Para suprir tal objetivo, têm-se como metodologia os trâmites da AD: seleção de Sequências Discursivas (SD), que materializam o discurso em texto e análise a partir dos pressupostos teóricos dessa linha de pesquisa com base em autores de linha pêcheuxtiana.

Com este estudo, espera-se mostrar que a fanfiction pode servir para fortalecer grupos excluídos e marginalizados, visto que eles escancaram a voz que possuem para fazer com

2 Tradução: ficção de fã.

3 Fator que a protege da acusação de plágio.

4 Paradoxalmente, a maioria dos influenciadores digitais que se torna protagonista em fanfics é do gênero masculino.

5 Por isso que, nesta pesquisa, o gênero feminino - intradiscursivo - estará em destaque no que se refere às produções de fanfiction, incluindo termos como as fãs, as autoras, dentre outros.

6 Pen name ou pseudônimo da autora (o gênero é inferido a partir do próprio posicionamento de gênero na escrita da autora). 
que outros lhes deem ouvidos, mesmo dizendo o que, na maioria das vezes, as mídias oficiais não querem escutar.

\section{(DES)MASCARANDO A AUTORIA}

Baseados em Pêcheux (2012, p. 56), podemos dizer que “Tudo não se pode dizer". A partir disso, retoma-se uma das discussões centrais no campo discursivo: a falta constituinte (ORLANDI, 1996, p. 12). Dessa forma, assim como quaisquer movimentos linguajeiros, as diversas narrativas ficcionais também apresentam essa falta. Melhor dizendo, toda obra, por mais "completa" que seja, mesmo desenvolvida em dezenas ou infinitos volumes, não dá conta de todo dizer. O desejo da fã surge, a princípio, dessa falta, dessa vontade de completude, do querer ter um "mundo semanticamente normal" (PÊCHEUX, 2002, p. 34) a partir de sua perspectiva. De forma consecutiva, a fanfiction se desenrola através do não-dito, tentando suprir as lacunas deixadas pelo criador da obra na qual se baseia. Assim, os movimentos simultâneos, a anterioridade e a posterioridade narrativa podem ser "preenchidos" em um processo infinito. Entretanto, como "preencher" uma história de vida? Nesse caso, parafraseando Pêcheux, afirmamos: Tudo não se pode viver.

Tendo como substrato o contato on-line com os influenciadores digitais - em redes sociais, principalmente, como o YouTube, o Instagram, o Facebook e o Twitter - as fãs acompanham a rotina de seus ídolos virtuais, tomando conhecimento de seus relacionamentos interpessoais, de seus costumes, de seu ambiente familiar. Além disso, atualmente, com ferramentas como os Stories ou Lives, a fã assiste ao dia a dia da personalidade, seguindo seus passos: o que come, onde está, com quem convive, que horário acorda/dorme, dentre outras ações que são registradas e tornadas públicas. Esse processo gera uma sensação de intimidade e faz com que a seguidora - fã - fique com expectativas referentes aos próximos "capítulos da história".

Desse modo, as fãs levam para o texto virtual as relações já existentes, podendo partir delas para criar conexões alternativas em relação ao mundo real, dentro de um campo de sentido possível. Isso porque, consoante Orlandi, (1996, p. 15), "Não é verdade que o texto possa se desenvolver em qualquer direção: há uma necessidade que rege um texto e que vem da relação com a exterioridade". Na produção narrativa - e, portanto, discursiva - há a necessidade de verossimilhança, de leitura do "real". Antecipando os sentidos acerca da realidade já publicada pelo influenciador digital, Titia_Little (2016) alerta suas leitoras na Sd1, que segue abaixo:

Sd1. 1. A história se trata da vinda do Cellbit para São Paulo, mais ou menos na mesma data que ele se mudou de verdade, mas assim como algumas coisas podem coincidir na história, já afirmo aqui que nem tudo é de acordo com a realidade. Então não venham com: “- Nossa, mas isso nunca aconteceu”; “- Nossa mas ele nem fez isso"; “- Isso está errado, ele nunca fez isso”. Porque já aviso desde já que me baseio em apenas ALGUNS FATOS DA REALIDADE. (TITIA_LITTLE, 2016, grifo da autora). 
Titia_Little (2016) insere alguns comentários, enumerados, nas notas da autora, que antecipam o primeiro capítulo da fanfiction "Cellbit, a vida com MITW", prevendo algumas reações que poderiam ser comentadas por suas leitoras. No tópico 1, contemplado pela Sd1, destaca-se a ligação da autora de fanfiction tanto com a tida "realidade" quanto com suas leitoras, pois, construindo sentidos outros, não familiares às demais fãs, Titia_Little afasta-se da "verdade", dos "fatos da realidade". Desse modo, quando Titia_Little avisa, de forma parafrástica - isto é, faz-se repetir em relação ao sentido trabalhado -, que haverá polissemia em sua construção - ou seja, sentidos outros - é como se dissesse: "Essa fanfiction não é uma biografia, não esperem isso dela”.

Além disso, ao mesmo tempo em que se afasta da "verdade", a autora mantém-se ligada a ela, visto que "algumas coisas podem coincidir na história" ao basear-se em "apenas alguns fatos da realidade", sendo estes, além de traços de enredo, personagens, ambientes, relacionamentos já existentes, entre outros. Isto é, "apenas alguns fatos da realidade" contempla a base narrativa, o já-lá que faz com que haja uma categoria específica de fandom ${ }^{7}$ e de leitoras possíveis para essa publicação, um ambiente já instaurado com base nos sentidos que já circulam.

Na produção da fanfiction, o real a respeito dos influenciadores digitais é visto como o que é publicado nas redes sociais, o que é possível seguir. As publicações do ídolo são a confirmação do real, os "fatos da realidade" em que se baseiam as fãs, como Titia_Little na Sd1. Dessarte, assim como alguns leitores desconsideram as fanfictions - baseadas em literatura - que não seguem o cânone literário, ou seja, uma narrativa fiel ao universo basilar da obra, as leitoras de fanfictions com influenciadores digitais, de igual forma, exigem uma ligação com a realidade, portanto, querem também a exibição da repetição, ou seja, querem uma paráfrase da vida de seu ídolo.

Essa repetição, por sua vez, discursivamente, torna-se presente de qualquer modo, já que, de acordo com Orlandi (1996, p. 70), “[...] podemos mesmo afirmar que o dizível é o repetível, ou melhor, tem como condição a repetição". Isso porque, para a $\mathrm{AD}$, o que é dito suscita sentido e somente o dizemos por já haver sentido, um já-lá. No entanto, sabemos que o repetível exigido pelas leitoras não é, exatamente, o mesmo no sentido diegético, pois, apesar de quererem acompanhar a personagem, desejam vê-la em novas peripécias, situações que se tornam possível no campo literário. Ademais, é importante destacar que "[...] em discurso, distintas materialidades sempre determinam diferenças nos processos de significação” (ORLANDI, 1996, p. 17), nesse sentido, o movimento da escrita sobre um influenciador digital já é, por si só, um engendrador de sentidos outros.

Ainda quanto à repetição, podemos verificar uma percepção singular nas fãs que escrevem fanfiction, dado que a base para a escrita é algo existente de forma consciente. Ou seja, parte-se do já-lá sem esquecer-se dele. No entanto, podemos verificar que o esquecimento ideológico, número um, aquele pelo qual, de acordo com Pêcheux (2014, p. 161-62), "temos a ilusão de ser a origem do que dizemos", ainda permanece, pois, ao movimentar os sentidos e dar outros direcionamentos à narrativa, a autora cria a ilusão de produção, de origem, sem considerar o interdiscurso que possibilita essas construções.

7 Comunidades de fãs destinadas a compor e acompanhar leituras paralelas à narrativa original. 
A partir da produção da fanfiction, há um novo que deriva dos sentidos publicados pelos influenciadores digitais nas mídias, assim, um movimento de interpretação é estabelecido e, segundo Orlandi (1996, p. 14), "diferentes formulações constituem novos produtos significativos”. A fã, em sua escrita, não deseja ser a origem de seu dizer, nem mesmo o fim deste. Ela rompe com essa ilusão, embora, paradoxalmente, ao mesmo tempo, crê ser a origem das narrativas paralelas à original, em outros termos, paralelas à vida do influenciador em questão. O que se tem, por fim, é um diferente do mesmo. Além disso, ao participar de um fandom, a fã deseja que as produções sobre o mesmo nunca acabem. Ela deseja uma narrativa, de seu próprio mundo, sem fim.

Sd2. 2. Eu quero e preciso muito que vocês comentem ao longo dessa minha Fic, eu juro que a minha primeira fic, fiquei muito desanimada, pois de 50 pessoas que liam, apenas 3 comentavam e quando eu perguntei se queriam uma $2^{\text {a }}$ temporada, ninguém, NINGUÉM me respondeu, eu iria fazer a $2^{\text {a }}$ temp, mas desanimei e encerrei a Fic, por motivos de: ninguém respondeu, ninguém comentou e desanimei (TITIA_LITTLE, 2016, grifos da autora).

Seguindo os tópicos das notas da autora, na Sd2, Titia_Little comenta a respeito de sua experiência em uma fanfiction anterior. Tendo em vista que no site em questão é possível acompanhar o número de visualizações, comentários e curtidas em cada capítulo, as autoras conseguem materializar os dados de suas publicações, podendo fazer uma média dos resultados.

Assim, na Sd2, podemos verificar a relação basilar que há entre autora - produtora da fanfiction - e leitoras. O universo fandom, estabelecido nas categorias de postagens, cria uma rede de relacionamentos que constituem as produções de fanfictions. As autoras, tanto em notas anteriores quanto em notas finais, conversam com suas leitoras, além de responder, geralmente, a todos os comentários postados, que dialogam com os capítulos da narrativa. Dessa forma, o desenrolar da trama, da inspiração, da identificação como autora, faz-se e fortalece-se. Além de que, podemos afirmar que uma autora acompanha a outra, comenta os capítulos da outra e vice e versa, mantendo a conexão das tramas. Com base nisso, Jamison (2017, p. 27) afirma que "As linhas de enredo se cruzam, se tornam confusas, criam padrões - se não nas histórias individuais, então geralmente na cabeça dos leitores. A fic experimentada desta forma se parece mais uma rede (algo bem apropriado) do que a uma série".

Na fanfiction, nada é individual, pois ela se baseia no sentido coletivizado. Parte-se de um sentido prévio - personagem basilar -, desenrola-se a partir de sentidos (outros) inseridos como desejos nos comentários e cruza-se com o sentido já previsto pela própria autora da narrativa. Essa relação é constitutiva do/no sujeito, pois “[...] na interpelação do indivíduo em sujeito está inscrita a relação do eu e o outro, do eu e o Outro" (ORLANDI, 2017, p. 296). Por consequência, em um fandom, estabelece-se uma relação rizomática, não tendo início marcado nem fim, pois Deleuze e Guattari (2011, p. 48) afirmam que "Um rizoma não

8 Disponível em: <https://www.spiritfanfiction.com/>. Acesso em: 15 jan. 2020. 
começa nem conclui, ele se encontra sempre no meio, entre as coisas, inter-ser, intermezzo", uma relação de devir. Assim sendo, a autora, ao publicar sua narrativa, já se insere em um entremeio e precisa dele para se consolidar.

Titia_Little, ao relatar a experiência na fanfiction anterior, confessa seu desânimo (de modo repetido) em relação à falta de respostas e, com isso, abre-se a suas leitoras afirmando que "quero e preciso muito que vocês comentem ao longo dessa minha Fic". O querer e o precisar aparecem como súplica às leitoras, um pedido por comentários, retornos a respeito de uma fanfiction que pretendia, já em seu primeiro capítulo, alongar-se. Podemos ver o pedido de Titia_Little como uma linha de fuga em relação ao resultado anterior - rompimento com a produção -, uma linha de fuga para poder continuar em autoria. No pronome indefinido "NINGUÉM", assim, em caixa alta, repetido diversas vezes na Sd2, exige-se, de maneira intradiscursiva, o rizoma, a conexão para sustentação - esse "NINGUÉM" deve, portanto, deixar de existir para eliminar a indeterminação de seus coenunciadores.

Em contrapartida, em publicações editoriais, o retorno a respeito dos exemplares vendidos e, consequentemente, aceitação da clientela só é visível após um determinado período de tempo, geralmente, em médio ou longo prazo. Devido a isso, muitos autores acabam sendo reconhecidos como tais somente postumamente. No caso da internet, o retorno de que a autora precisa pode ser instantâneo, uma motivação para continuar na produção da rede de sentidos. Além disso, antes mesmo de publicar a continuidade da narrativa - próximos capítulos - as leitoras, quando conectados ao rizoma, pedem por tal ação, questionam o movimento de sentidos conduzidos pela narrativa, acompanham a produção de perto, muitas vezes trocando mensagens privadas com a autora, ou seja, a conexão rizomática de que falamos, realiza-se. Demarca-se, assim, a relação permanente entre o eu e o outro (tanto o outro leitora quanto o eu influenciador digital que motiva a escrita).

Podemos verificar a importância do universo fandom, enquanto rizoma, a partir do caso de Titia_Little, visto que, em sua primeira fanfiction, "What Goes Around Comes Arou$n d "$ " a autora não obteve, conforme a $\mathrm{Sd} 2$, o retorno esperado, encerrando a narrativa com 15 capítulos e 18 comentários. Já em sua segunda fanfiction, "Cellbit, a vida com MITW", iniciada em junho de 2016, a autora contou, após a publicação de 153 capítulos, com 4193 comentários, o que comprova a força da coletividade na produção de fanfictions. Além disso, após o início da publicação de "Cellbit, a vida com MITW", Titia_Little produziu mais três narrativas ${ }^{10}$, o que mostra a potência da colaboração autoral.

A autoria na produção de fanfiction, além do já mencionado, revela-se de modo diverso, visto que: a) as produções não se limitam ao esperado/encomendado por editoras; b) as narrativas não precisam enquadrar-se à cultura oficial, podendo, dessa forma, contemplar relações não normativas; c) os apelidos são usados tanto na postagem das histórias quanto no ato dos comentários, ou seja, é permitido o anonimato. Todos esses fatores permitem uma produção que extrapola o normatizado, seja pela escola, seja pela mídia. Desse modo, o que se lê em uma fanfiction não é encontrado nas prateleiras das livrarias, e isso tem

9 Disponível em: <https://www.spiritfanfiction.com/historia/what-goes-around-comes-around-5562922>. Acesso em: 16 jan. 2020.

10 Disponível em: <https://www.spiritfanfiction.com/perfil/little_smart/historias>. Acesso em: 10 jan. 2020. 
cativado diversas leitoras e escritoras que se veem em um universo paralelo ao que se diz "publicável”.

Esse aspecto identifica-se com o que Pêcheux (2012, p. 100) chama de criatividade, pois, segundo a definição do autor, esta é “a característica do próprio sistema linguístico de permitir deslocamentos históricos dentro do campo das formulações possíveis”. Incluímos aqui, em relação ao histórico, a produção da fanfiction, pois ela promove relações, interpretações e, por suposto, sentidos e historicidade - narratividade. Além do mais, Agustini e Grigoletto afirmam que

[...] a escrita não pode ser separada nem da história nem do sujeito, uma vez que é na escrita que se materializam os fios da história, os quais determinam os modos de individualização (subjetivação) do sujeito. E esse espaço de subjetivação é tenso, contraditório, atravessado pela alteridade. (AGUSTINI; GRIGOLETTO, 2008, p. 148)

Alteridade esta que se materializa na produção da fanfiction, pois, para além do ideológico, da heterogeneidade constitutiva, de acordo com Authier-Revuz (1990, p. 29), a heterogeneidade mostrada faz-se predominante no movimento de autoria estabelecido na fanfiction, uma autoria colaborativa, rizomática, que se consolida (in)conscientemente a partir de um já-lá.

O Outro e os outros são constitutivos do sujeito e também por ele são constituídos. Dessa forma, ao mesmo tempo em que a autora se mascara com o pen name - uma máscara para subversão -, desmascara-se ao subjetivar-se e constituir-se como sujeito diante dos outros, em uma relação que não se finda. Esse movimento é ratificado nos fandons, pois além dos aspectos inter e intradiscursivos, a autoria se faz em relação à leitora que comenta, encontra-se, constitui a obra e, por consequência, subjetiva-se e subjetiva a autora.

Além disso, com a máscara do anonimato, o sujeito pode se desmascarar e se mostrar verdadeiramente a partir das narrativas que, em tese, não seriam divulgadas se fosse obrigatório o uso do próprio nome. Isto é, esse modo de produção e compartilhamento de histórias permite que minorias se mostrem em sua potência, seja no que se refere ao feminino (cis e trans), seja no que toca as relações afetivas, contemplando a diversidade não-normativa LGBTQIA+. E é justamente a partir disso que conexões outras se permitem em um rizoma que possibilita a constituição e a potencialização dos sujeitos envolvidos.

Nesse sentido, Pêcheux afirma:

[...] é porque há o outro nas sociedades e na história, correspondente a esse outro próprio ao linguajeiro discursivo, que aí pode haver ligação, identificação ou transferência, isto é, existência de uma relação abrindo a possibilidade de interpretar. E é porque há essa ligação que as filiações históricas podem-se organizar em memórias, e as relações sociais em redes de significantes. (PÊCHEUX, 2002, p. 54) 
As memórias construídas se renovam e se fazem presentes no discurso autoral, que, necessariamente, é composto por repetição e por interpretação. Ao mesmo tempo, o novo aparece a partir de conexões outras também realizadas por meio do interpretável - o que vem do Outro, dos outros - da origem do universo narrativo escolhido e dos comentários que dialogam com o delineamento narrativo. Isso porque, segundo Orlandi (2017, p. 292), "o gesto de interpretação é afetado e afeta a relação com a alteridade" e, com isso, podemos dizer que há subjetivação, narratividade que faz com que o sujeito se conte e se modifique.

Ademais, é importante sublinhar que, consoante Orlandi (1996, p. 18-19), a interpretação sempre se dá em um determinado momento e lugar que acabam por direcioná-la, desse modo, tornando-a política. Assim, o político se manifesta nos movimentos de sentido suscitados pela interpretação, até mesmo porque a relação do sujeito com a linguagem se constrói de acordo com as condições de produção determinadas pelo seu tempo/posição histórico-social (ORLANDI, 2001, p. 77). Outrossim, é válido destacar que a produção da fanfiction manifesta-se como um movimento de resistência em relação aos sentidos estabelecidos, aos relacionamentos e ações normatizadas, desviando-se do comumente esperado.

Para Orlandi (2015, p. 28), as condições de produção se dão no sentido estrito, ou seja, "as circunstâncias da enunciação" - quem fala, para quem fala, etc. -; e no sentido amplo, que se relaciona com o contexto histórico, social, cultural, ideológico, etc.

A partir da $\mathrm{Sd}$ 2, podemos constatar dois momentos distintos de produção em relação a seu sentido estrito, um sem retorno das leitoras e outro com, o que, consequentemente, interfere na produção e constância de publicação na autoria da fanfiction.

No sentido amplo, a publicação das fanfictions hoje, via internet, anonimamente, possibilitam sentidos outros que, em tempos diversos, seriam silenciados pela censura. Partindo desse ponto, verifica-se na autoria da fanfiction um deslocamento ao esperado que gera uma transgressão em virtude do "real" e do "virtual". A transgressão quanto ao "real" ocorre porque, partindo de uma personalidade existente, como já dissemos, a autora da fanfic elabora desencadeamentos narrativos - ações e relacionamentos, principalmente - não condizentes com a realidade divulgada pelo ídolo em questão. No que se refere ao virtual, o enredo não necessariamente segue o que é postulado pelas fãs, que se fazem ativas nos comentários. Além disso, o desenrolar dos relacionamentos desemboca, em muitos casos, no aspecto sexual, permitindo, à autora e às leitoras, a construção de cenas que geralmente não ganham grande circulação no meio editorial, principalmente porque, por diversas vezes, os relacionamentos são homossexuais.

Desse modo, mesmo estando à margem do que se vê nas prateleiras, a fanfic dá a ver sentidos outros, não normatizados, que fazem com que a realidade das minorias seja abordada e visibilizada. A fanfiction possibilita a representatividade em relação àquilo que se apaga nas narrativas comerciais devido a não adequação no que se vê como normativo. E é nesse ponto em que se vê a transgressão. Como dito, ao mesmo tempo em que há máscara, a partir de apelidos, há a ação de desmascarar-se, de dar a ver aquilo que faz sentido para diversas pessoas que não são colocadas em cena.

Desse modo, a fã, para constituir-se autora - uma fã-autora - a partir de sua produção textual, (in)conscientemente, não lida apenas com os critérios estabelecidos pela linguística para a constituição do texto, visto que, consoante Orlandi (2017, p. 312), "[...] a amarra do 
texto como unidade não é coesão ou coerência, nem integração a uma totalidade; é a parte do processo de significação e, em sua constituição, entra, entre outros, o que defino como narratividade". Assim, pode-se perceber o funcionamento da narratividade/historicidade nos movimentos discursivos que engendram as fanfics, pois a autoria em um ambiente fandom ocorre por meio de sentidos instalados/esperados, partindo do já constituído para a transgressão.

Para Orlandi,

Pela observação da narratividade flagramos a inscrição do(s) outro(s) no discurso do sujeito, assim como a determinação mais ampla da voz do Outro (interdiscurso, ideologia) presente no espaço de interpretação do sujeito individuado. O funcionamento da memória no sujeito se faz pela narratividade. (ORLANDI, 2017, p. 309)

O sujeito assim, ao construir sentidos, o faz em relação aos outros -coenunciadores por meio de movimentos de antecipação em que "se confrontam a história do dizer do autor e a história de leituras do leitor" (ORLANDI, 1996, p. 75). Durante o processo enunciativo, o sujeito movimenta os sentidos utilizando, de acordo com Orlandi (2015, p. 37), "mecanismos de antecipação". Ou seja, o sujeito se coloca no lugar do coenunciador, para que, dessa forma, possa tentar construir argumentos que atinjam os sentidos pretendidos. Segundo Orlandi (2015, p. 37), ainda se utiliza, inconscientemente, a relação de forças manifestada no discurso, porque o local de sua fala também faz com que os sentidos sejam movimentados de uma ou outra forma. Dessa maneira, podemos retomar a Sd2 que demarca a necessidade evidenciada por Titia_Little, pedindo às leitoras retorno em relação à narrativa, dizendo que, na fanfiction anterior, havia parado por falta de comentários. Isto é, a autora, ao manifestar-se, estabelece uma condição para sua produção: precisa de interação, de comentários, pois, caso contrário, como evidenciado, abandonaria a narrativa. O que gerou a concretização do significado antecipado. Com isso, podemos verificar que o diálogo faz-se presente na construção da fanfiction, o que também a diferencia de publicações "originais".

Para Agustini e Grigoletto (2008, p. 153), “Se pensarmos na 'originalidade', enquanto um aspecto da autoria relativo ao inusitado, é possível compreender o autor como uma forma de efeitosujeito, que, ao transgredir via escrita a ordem instituída, (se) corporifica (n)a escrita, fazendo-se singular". A autora de fanfic produz algo singular e se singulariza por meio da escrita e do rompimento com o delimitado da vida real. Além disso, Orlandi afirma que

É só no imaginário que todas estas versões, digressões, formulações, partiriam de um texto "original". Nesse sentido, o texto "original" é uma ficção, ou melhor, é uma função da historicidade, num processo retroativo. São sempre vários, desde a sua "origem", os textos possíveis num "mesmo" texto. (ORLANDI, 1996, p. 14)

A partir dessa consideração, não poderíamos mais distinguir a fanfiction em relação ao texto original, visto que são sempre vários textos em um mesmo. No entanto, nesta pes- 
quisa, direcionamo-nos à produção de narrativas baseadas na vida "real" - real que se intercruza com o digital, um digit(re)al -, e, nesse caso, o texto original faz-se vivo, partindo, na maioria das vezes, da própria fala do influenciador digital em questão. Ao mesmo tempo, essa fala não é, de acordo com a perspectiva da $\mathrm{AD}$, isolada em si, dado que ela só se faz possível devido a outras falas, textos outros que se materializam no hoje, desse modo, também não se caracteriza como original. Assim, se considerarmos a efetivação da autoria a partir da procura do original, não a encontraríamos, pois sempre há um já-lá. Para Orlandi (1996, p. 11), "Consideremos o fato de que o dizer é aberto. É só por ilusão que se pensa poder dar a 'palavra final'. O dizer também não tem um começo verificável: o sentido está (sempre) em curso". Dessa forma, podemos verificar os indícios de autoria, não buscando um início ou um fim, mas sim quando há movimentos de interpretação, construção de sentidos outros que rompem com o (pré)estabelecido.

A partir das condições de produção da fanfiction - anonimato, publicação digital - o desenrolar narrativo pode desenvolver movimentos de autoria que fogem ao padronizado pelas instituições e rompem com os poderes estabelecidos. Ao mesmo tempo em que se preservam aspectos textuais, em relação ao tipo e gênero textual - já-lá -, enredos outros são possíveis, permitindo a produção de sentidos que desestabilizam o mercado editorial. Na produção de fanfiction, além de não haver um retorno financeiro em relação ao texto publicado, há relações colaborativas não comerciais: equipes coordenadoras de sites, beta readers ${ }^{11}$, $_{\text {capistas }}{ }^{12}$, aulas de escrita ${ }^{13}$, tudo gratuito, promovendo o movimento de escrita e a construção autoral não institucional, tanto no site utilizado nesta pesquisa quanto nos demais. Além disso, como já destacado, a autora de fanfiction não pretende ser a origem do dizer, visto que já parte, conscientemente, do já conhecido. E, assim, é válido reafirmar que o sentido se faz porque já há sentido. Então, parte-se, sempre de um já-lá, mas, nesse caso, possibilita-se o outro, a transgressão.

\section{CONSIDERAÇÕES FINAIS}

Tendo em vista o que foi explicitado nesta pesquisa, foi possível verificar as particularidades que caracterizam as fanfictions. Como visto, é justamente na margem, fora do mercado e da institucionalização, que essa produção se concretiza e se perpetua, rompendo o pré-estabelecido tanto na ficção quanto na própria vida, como a fanfic desta pesquisa.

A autoria de fanfictions consegue transgredir por meio das lacunas deixadas pelo próprio discurso e produz o que não seria autorizado de forma nominal, editorial e comercial.

11 "São usuários que participam do Fanfics e se disponibilizam a ajudar outros usuários com seus trabalhos (fanfics) no canal, indicando o que pode ser melhorado gramaticalmente, dando opiniões críticas construtivas através de comentários e os auxiliando com suas dúvidas, referente ao canal". Disponível em: <https://www.spiritfanfiction.com/jornais/ projeto-fix-it-ortografia-12533285>. Acesso em: 15 jan. 2020.

12 "Usuários que se disponibilizam a fazer capas". Disponível em: <https://www.spiritfanfiction.com/forum/topico/capa-das-historias-39709>. Acesso em: 15 jan. 2020.

13 Disponível em: <https://www.spiritfanfiction.com/aulas >. Acesso em: 15 jan. 2020. 
Em outras palavras, podemos considerar as fãs autoras (des)mascaradas, pois elas produzem novos sentidos e transgridem o estabelecido para potencializar o que, assim, não fica mais à margem do possível. 


\section{REFERÊNCIAS}

AGUSTINI, Carmen Lúcia Hernandes; GRIGOLETTO, Evandra. Escrita, alteridade e autoria em Análise do Discurso. Matraga, Rio de Janeiro, v. 15, n. 22, jan./jun. 2008. Disponível em: <http://www. pgletras.uerj.br/matraga/matraga22/arqs/matraga22a08.pdf >. Acesso em: 10 jan. 2020.

AUTHIER-REVUZ, Jacqueline. Heterogeneidade enunciativa. Cad. Est. Ling. v. 19, p. 25-42, jul./dez. 1990. Disponível em: <https://periodicos.sbu.unicamp.br/ojs/index.php/cel/article/ view/8636824/4545>. Acesso em: 10 jan. 2020.

DELEUZE, Gilles; GUATTARI, Felix. Mil platôs: capitalismo e esquizofrenia. 2. ed. Rio de Janeiro: Editora 34, 2011. v. 1.

JAMISON, Anne. Fic: por que a fanfiction está dominando o mundo. Rio de Janeiro: Anfiteatro, 2017.

ORLANDI, Eni Pulcinelli. Interpretação; autoria, leitura e efeitos do trabalho simbólico. Petrópolis: Vozes, 1996.

ORLANDI, Eni Pulcinelli. Nem escritor, nem sujeito: apenas autor. In: ORLANDI, Eni Pulcinelli. Discurso e leitura. 6 ed. São Paulo, Cortez, 2001.

ORLANDI, Eni Pulcinelli. Análise de discurso: princípios e procedimentos. 12. ed. Campinas: Pontes, 2015.

ORLANDI, Eni Pulcinelli. Eu, Tu, Ele: discurso e real da história. Campinas: Pontes, 2017.

PÊCHEUX, Michel. O Discurso: estrutura ou acontecimento. 3 ed. Campinas: Pontes, 2002.

PÊCHEUX, Michel. Análise de discurso. 3 ed. Campinas: Pontes Editores, 2012.

PÊCHEUX, Michel. Semântica e discurso: uma crítica a afirmação do óbvio. 5. ed. Campinas: Editora da UNICAMP, 2014.

TITIA_LITTLE. A Viagem. In: TITIA_LITTLE. Cellbit, a vida com MITW. 18 jun. 2016. Disponível em: <https://www.spiritfanfiction.com/historia/cellbit-a-vida-com-mitw-5797303/capitulo1>. Acesso em: 16 dez. 2019. 